\title{
HEALTH SYSTEMS: A DYNAMIC SYSTEM-BENEFITS FROM SYSTEM DYNAMICS
}

\author{
Patrick Koelling \\ Michael J. Schwandt \\ Grado Department of Industrial and Systems Engineering \\ 250 Durham Hall \\ Virginia Tech \\ Blacksburg, VA, 24061, U.S.A.
}

\begin{abstract}
Operations researchers, industrial engineers, and simulation analysts have applied their knowledge and skills to the health care system for a long time. This complex system needs their help today more than ever. The ever-growing need to understand and improve system performance challenges researchers to apply all the tools at their disposal. One of these tools that is getting increased attention is system thinking, with its application partner system dynamics. This paper presents a glimpse into the system thinking world as it is currently applied in the health care arena, and provides some thoughts on new directions for application. While there are other very useful tools, such as optimization and discrete-event simulation, that are effectively used for health care application, they should not always be the tools of choice, and suggestions are made for when system dynamics may be more appropriate for a particular application.
\end{abstract}

\section{INTRODUCTION}

Health care is a subject that seems to continuously bombard our senses and pervade our culture. The popular media regularly print, say, and show current issues in health care, reiterate the current "crisis" we're in, argue for or against major change, and fill us with a barrage of data to support or refute one cause or another. It seems the more we "tinker" with the system, the worse the situation gets.

The health care system is large and complex, one that does not naturally lend itself to easy analysis, design, or even understanding. The complexity and critical nature of the system beg for the development and use of good, representative models.

As Hirsch et al. (2005) state, a theory is needed to explain what created the current set of problems that exist in the U.S. health care system and why efforts at reform have largely failed. To this end different philosophical bases for reform and the need for an eclectic approach should be considered.

\section{HEALTH SYSTEM MODELING}

System dynamics (SD) is generally used in association with a simulation of the system in question. Given the complexity of most systems, development of the SD model focuses on a subset of the real world system, with the inclusion criteria driven by the particular problem being addressed by the modeler.

One often hears people talking about "systems thinking." However, more often than not they are implying simply that one needs to look at the entire system, not just one piece of the system. This is certainly a step in the right direction, but goes only so far.

It is important to truly understand that everything is connected to everything else. This concept of systems thinking, complete with feedback, complexity, and nonlinearity, is captured through the development of causal loop diagrams, which demonstrate how the structure of the system is contributing to the results of the system processes. With the addition of quantitative data, the stocks and flows needed for a system dynamics simulation can be utilized to further analyze the system.

This type of systems thinking is essential to understanding the structure of the system being examined, and it is the system structure that defines system behavior. This often leads to the "aha!" moments when one finds a counterintuitive result. Perhaps more than anything else, increased use of systems thinking tools can help to explain why systems continue to deliver the same results when only some parameters in the system are changed, rather than addressing the fundamental structure of the system.

\section{SYSTEM DYNAMICS VS. DISCRETE EVENT}

Not surprisingly, many system problems can be addressed with a variety of modeling techniques, including SD mod- 
eling. This naturally leads to a decision about using SD or discrete-event simulation (DES). The decision to choose between DES or SD often seems to be made based on an unknown, or at least unstated, user preference function.

However, DES seems to work well for issues that are concerned with transactions, processing, and the flow of individual entities through a system. These are more usually associated with operational level types of problems. Regular attendees at Winter Simulation conferences are well aware of this valuable use of simulation. The world of DES is quite broad and diverse, with an essentially unlimited pool of applications.

With respect to health care, such applications have been described in papers at many past Winter Simulation conferences. In fact, WSC 2004 had a Biotechnology/Health Care track that attracted some thirteen papers, with applications ranging from renal transplant waiting lists, to emergency department performance, to modeling cell division. Since 2000, at least 38 papers of health care applications have been presented at Winter Simulation conferences. While different model types and approaches are presented in these papers, all follow the basic foundation of Monte Carlo or DES. Some examples of these include patient processing in an emergency department and assessment of staff schedules.

$\mathrm{SD}$, on the other hand, is typically used for models that represent relationships between system variables, rates of change over time, and explicit feedback. Rather than focusing on individual transactions in the system, the models focus more on the levels of variable stocks and the flows between variable states. As a result, SD models are more often associated with higher level types of problems, especially consideration of the impact of policy and strategy decisions. A review and summary of applications in health care is provided in Section 3.

Morecroft and Robinson (2005) compared the use of SD and DES from a variety of perspectives including technical differences, relative level of detail, capability for showing information feedback, and conceptual differences. Lane (2000) focused on conceptual differences between SD and DES (Table 1). These conceptual differences can offer particular insight when considering the appropriate modeling approach for health systems, particularly where there is a history of discrete-event modeling activity.

While Morecroft and Robinson (2005) summarize the various comparisons between SD and DES, they recognize that each comparison comes from the perspective of either a SD or DES specialist.

In dealing with change we need to get beyond the tactical level to confront the issue of what problem we're really trying to solve. By understanding the differences at the conceptual level we can ask better questions about the problem under investigation. Ultimately we have a better understanding of the explanations and insights that these approaches offer, leading to the proper selection of the proper technique at the proper time.

Table 1: Conceptual Differences between DES and SD (Lane 2000).

\begin{tabular}{|c|c|c|}
\hline & $\begin{array}{ll}\text { Discrete } & \text { Event } \\
\text { Simulation } & \\
\end{array}$ & System Dynamics \\
\hline Perspective & $\begin{array}{l}\text { Analytic; emphasis } \\
\text { on detail complex- } \\
\text { ity }\end{array}$ & $\begin{array}{l}\text { Holistic; emphasis on } \\
\text { dynamic complexity }\end{array}$ \\
\hline $\begin{array}{l}\text { Resolution } \\
\text { of models }\end{array}$ & $\begin{array}{l}\text { Individual entities, } \\
\text { attributes, decision } \\
\text { and events }\end{array}$ & $\begin{array}{l}\text { Homogenised enti- } \\
\text { ties, continuous pol- } \\
\text { icy pressures and } \\
\text { emergent behaviour }\end{array}$ \\
\hline $\begin{array}{l}\text { Data } \\
\text { sources }\end{array}$ & \begin{tabular}{lr}
\multicolumn{2}{l}{ Primarily numeri- } \\
cal with some \\
judgemental ele- \\
ments
\end{tabular} & Broadly drawn \\
\hline $\begin{array}{l}\text { Problems } \\
\text { studied }\end{array}$ & Operational & Strategic \\
\hline $\begin{array}{l}\text { Model } \\
\text { elements }\end{array}$ & $\begin{array}{l}\text { Physical, tangible } \\
\text { and some informa- } \\
\text { tional }\end{array}$ & $\begin{array}{l}\text { Physical, tangible, } \\
\text { judgemental and in- } \\
\text { formation links }\end{array}$ \\
\hline $\begin{array}{l}\text { Human } \\
\text { agents rep- } \\
\text { resented in } \\
\text { models as } \\
\end{array}$ & Decision makers & $\begin{array}{l}\text { Boundedly rational } \\
\text { policy implementers }\end{array}$ \\
\hline $\begin{array}{l}\text { Clients } \\
\text { find the } \\
\text { model }\end{array}$ & $\begin{array}{l}\text { Opaque/dark grey } \\
\text { box, nevertheless } \\
\text { convincing }\end{array}$ & $\begin{array}{l}\text { Transparent/fuzzy } \\
\text { glass box, neverthe- } \\
\text { less compelling }\end{array}$ \\
\hline $\begin{array}{l}\text { Model } \\
\text { outputs }\end{array}$ & $\begin{array}{l}\text { Point predictions } \\
\text { and detailed per- } \\
\text { formance measures } \\
\text { across a range of } \\
\text { parameters, deci- } \\
\text { sion rules and sce- } \\
\text { narios }\end{array}$ & $\begin{array}{l}\text { Understanding of } \\
\text { structural source of } \\
\text { behaviour modes, lo- } \\
\text { cation of key per- } \\
\text { formance indicators } \\
\text { and effective policy } \\
\text { levers }\end{array}$ \\
\hline
\end{tabular}

\section{A REVIEW AND SUMMARY OF THE SYSTEM DYNAMICS LITERATURE ON HEALTH CARE}

System dynamics papers have been published in a variety of journals worldwide. Fortunately for researchers, the Systems Dynamic Society (SDS) maintains a bibliography of publications that feature system dynamics research and applications. The current bibliography contains 7,754 records from the mid-1960's through the end of 2004. Due to the challenge in creating such a database, it is possible that trends in the data may be due to increased access to more recent records.

To assess the focus of system dynamics research and applications in health systems, the SDS bibliography was searched for related records. To include as many records as possible, the general terms "health" and "medicine" 
formed the basis of the search and generated 266 records for consideration.

The initial search results were refined to remove duplicate records and those records that were not actually related to health systems, but had used one of the search terms in the record description. 220 records remained for assessment.

\subsection{Assessment Approach}

The publications from the SDS bibliography were grouped into five-year periods, starting with 1965-1969 and extending through 2000-2004 (Figure 1).

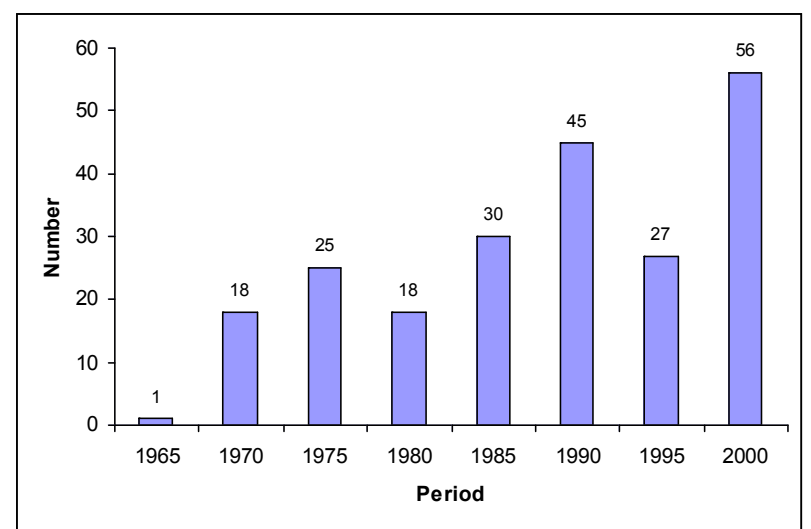

Figure 1: All Publications per Five Year Period (19652004)

The records were then assessed for alignment with the general health systems framework (Table 2). The framework's focus on geographic span suggests that the publications focusing on epidemiology, which crosses such borders, should be considered separately. In addition, fourteen publications related to dental health care were not considered as part of the health systems analysis.

62 publications focused on epidemiological issues were captured from the bibliography (Appendix). Half of those publications occurred between 1985 and 1994, when the primary topic was the spread of HIV/AIDS.

With the data available in the bibliography, an attempt was made to determine which country was the focus of each of the included publications. Only 32\% (71/220) of the publications could be so classified.

\subsection{Results}

With the epidemiology and dental health system records removed from the data, the publications display a more consistently increasing pattern over time (Figure 2).

When considered cumulatively, the publications are fairly well spread (Figure 3), except for the lack of consideration of prevention factors in the overall health system.
Table 2: General Health Systems Framework

\begin{tabular}{|l|l|}
\hline \multicolumn{1}{|c|}{ Category } & \multicolumn{1}{c|}{ Description } \\
\hline Health Systems & $\begin{array}{l}\text { Strategy and policy studies at } \\
\text { the national or international } \\
\text { level. }\end{array}$ \\
\hline Systems & $\begin{array}{l}\text { Strategic and policy studies, } \\
\text { typically within organizations, at } \\
\text { the regional or metropolitan area } \\
\text { level. }\end{array}$ \\
\hline Clinical & $\begin{array}{l}\text { Strategic and policy studies, } \\
\text { typically within organizations or } \\
\text { within a single facility. }\end{array}$ \\
\hline Delivery & $\begin{array}{l}\text { Tactically focused studies, typi- } \\
\text { cally within a single facility or a } \\
\text { department within a facility. }\end{array}$ \\
\hline Prevention & $\begin{array}{l}\text { Studies focused on the preven- } \\
\text { tion of illness, disease, or inci- } \\
\text { dents and the impact of preven- } \\
\text { tion strategies and tactics. }\end{array}$ \\
\hline Epidemiology & $\begin{array}{l}\text { Studies focused on the spread of } \\
\text { illness or disease or the physio- } \\
\text { logical understanding of an ill- } \\
\text { ness or disease. }\end{array}$ \\
\hline
\end{tabular}

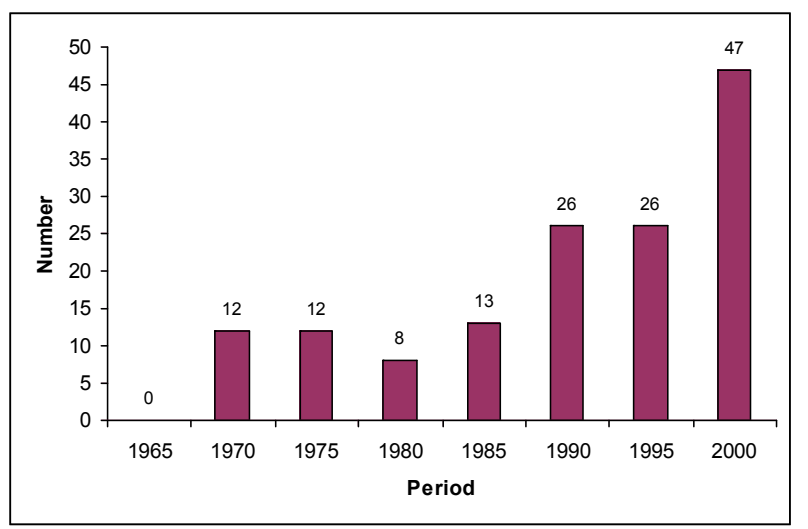

Figure 2: Publications per Five Year Period

As mentioned previously, the country or region benefiting from system dynamics research was identified for 71 of the 220 included publications. When the dental and epidemiological publications were removed, 50 publications remained. Of those, 26 were focused in Europe, with half of those in the United Kingdom. The United States was the focus of the work in 13 publications.

\subsection{Literature Summary}

Analysis of the bibliography indicates increasing interest in health systems research, although consideration of illness or disease prevention has not been subject to significant research. Even if epidemiological studies are con- 
sidered as prevention-focused, these studies have not been documented at increasing rates since 1995. The literature indicates a stronger interest in health care systems than the overall health system, which would bring a stronger focus to individual or population health.

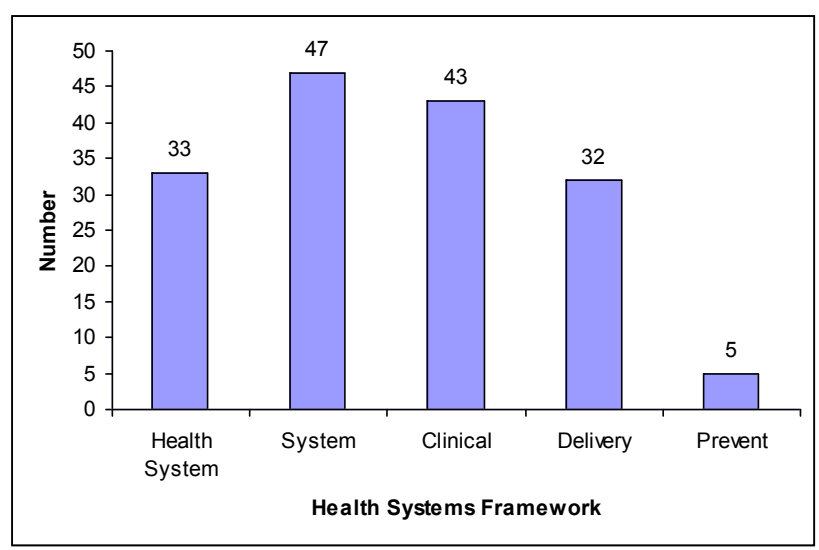

Figure 3: Publications by Health Systems Framework Category

The data do not support consistent determination of whether the studies are focused on qualitative or quantitative modeling. In many instances, the qualitative models (focusing on causal loop diagram development) provide significant opportunities by exposing the system structure. However, the quantitative analysis can extend the value of the modeling process.

Since the opportunity to assess the structure of qualitative models provides opportunities not readily available when discrete event simulation models are developed, further assessment of the qualitative versus quantitative distinction should be pursued.

\section{THE CASE FOR INCREASED SYSTEMS DYNAMICS MODELING IN HEALTH SYSTEMS}

A critical step in understanding and improving any aspect of the health care system is adequately representing the structure, or architecture, of the system. We have presented (Table 2) a rudimentary framework that is limited in its ability to represent the health system and provides little insight into the structure of the health system, and therefore reveals little about how the structure contributes to the behavior.

Causal loop diagrams, the underlying structure of systems thinking, provide a powerful way to represent the health system architecture. For example Hirsch et al. (2005) explore the health system from the perspective of population health dynamics (Figure 4).

The authors expand the basic model to consider the effects of things such as high tech medicine, fragmentation of services, cost containment, living conditions, and patient involvement. Their proposed model integrates all of these effects rather than considering them individually, demonstrating a strength of SD modeling.

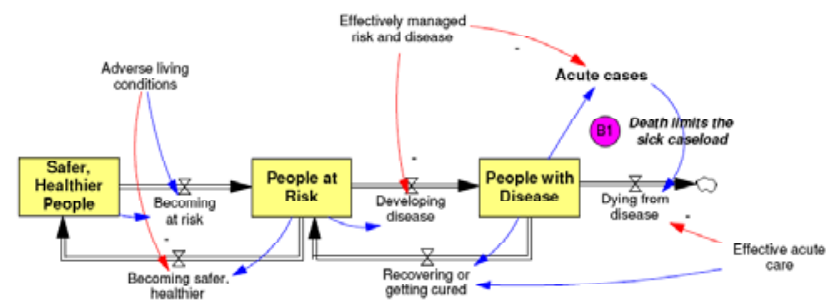

Figure 4: Population Health Dynamics (Hirsch et al. 2005)

An additional benefit of SD modeling is policy analysis. In any simulation exercise, one evaluates "policies." In typical DES applications, the policies considered may be things such as routing decisions, staff schedules, special queue handling, and so on. These policies can have a large effect on system performance.

The types of policies that SD typically considers are higher-level, focusing more on the effect of the structure and possible changes to that structure. SD provides a better tool set for assessing these kinds of policy recommendations. In addition, SD provides a natural learning environment, reflecting the dynamic nature of any system. Done properly, the model building exercise increases system understanding, and learning, of those who participate in constructing the model-yet another benefit of SD modeling.

To adequately understand, and thereby improve a system, it may be useful, or even necessary, to combine SD with DES to allow a myriad of policy decisions to be more effectively evaluated. Research to support the SD/DES combination is being conducted by several researchers. Increased computing power has allowed for the development of software tools that will allow for more effective integration of these modeling techniques.

\section{CONCLUSIONS}

With reference to both costs and quality, the U.S. health system has performed unsatisfactorily for years and efforts to improve the system have fallen woefully short (Porter 2004). The traditional tools for increasing understanding of system performance have not proven successful at achieving breakthrough performance within this environment. Therefore, other tools must be investigated and applied to health system performance improvement.

While system dynamics applications in health systems have been developed for almost 40 years, only in the past five years has the research at the regional and national health systems level significantly increased, although not in the United States. At these levels, integrated policies 
can be effectively modeled, leading to broad, dramatic improvements in health system performance.

Perhaps not surprisingly given the flow of money through the health care system, research from the personal perspective, focusing on individual or group healthiness, rather than on the performance of the system to maintain health when it declines, has been lacking. Since 1970, only five SD-based studies focusing on illness or disease prevention have been documented. However, the systems thinking focus on the overall system suggests that this is fertile research ground, particularly as the availability of health care resources becomes more limited.

Systems thinking and system dynamic modeling focus on understanding the structure of a system and how that structure impacts behavior over time. Focusing on the U.S. health system, Hirsch et al. (2005) have demonstrated the potential benefits that increased utilization of SD modeling can contribute to significant structure-based performance improvement. Even their initial models focus more on the health care system than the overall health system.

The opportunities that exist to apply SD modeling in health systems performance improvement start with the qualitative models that Hirsch et al. have developed. They correctly state that a key avenue of research is to build from their causal loop diagrams, adding the necessary stock and flow data to support quantitative analysis.

In addition, the strengths of discrete event simulation must continue to be exploited to generate improvement opportunities. However, research indicates even more benefits can be obtained by efficiently and effectively integrating SD and DES models to take advantage of the strengths of both techniques.

\section{ACKNOWLEDGMENTS}

The authors wish to acknowledge the support provided by John Grado through the John Grado Fellowship, and Dr. David Eitel of York Hospital for his continued support and encouragement of our ongoing research into the vast world of health system improvement.

\section{APPENDIX: PUBLICATIONS PER FIVE YEAR PERIOD BY HEALTH SYSTEMS FRAMEWORK CATEGORY}

The data in Figures A-1 through A-7 represent numbers of publications, per five-year period, that correspond to the different foci of study described in each. The data come from the System Dynamics Society bibliography as previously cited.

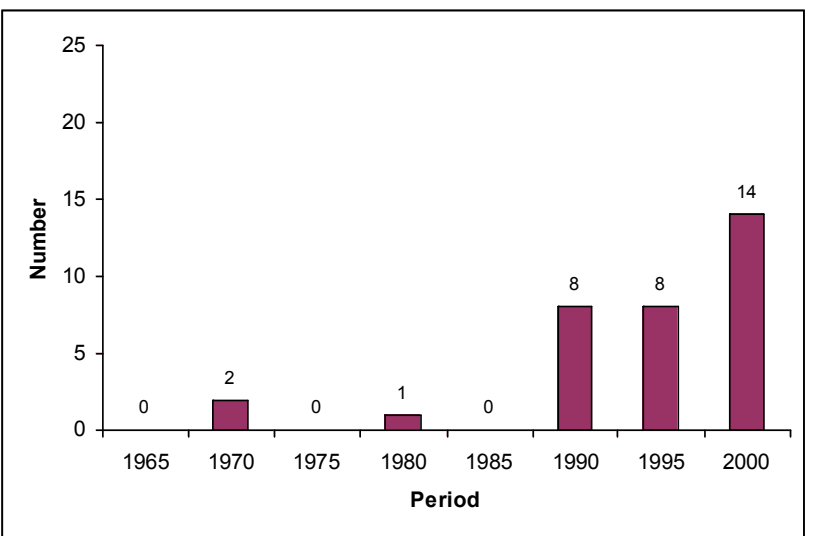

Figure A-1: Health Systems

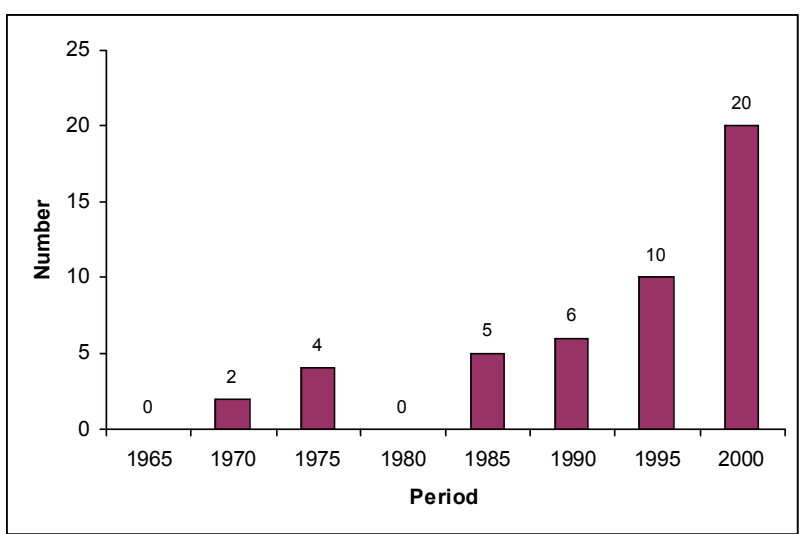

Figure A-2: Systems

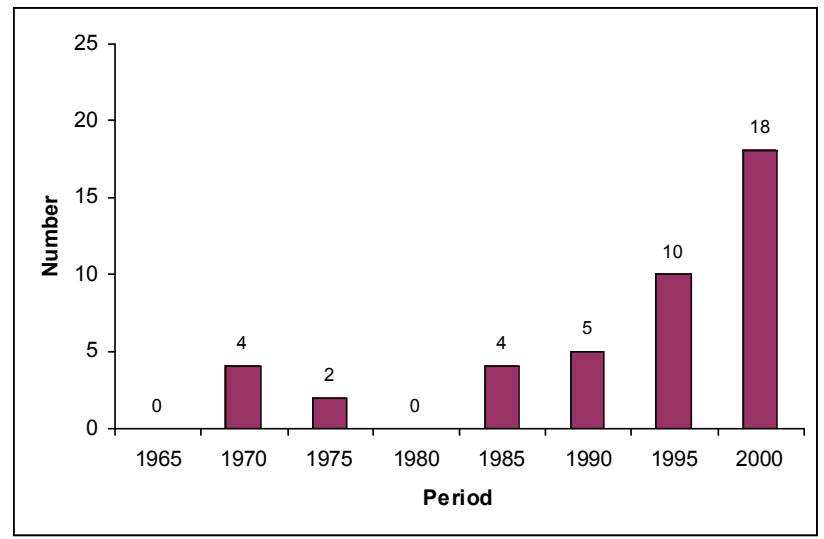

Figure A-3: Clinical 


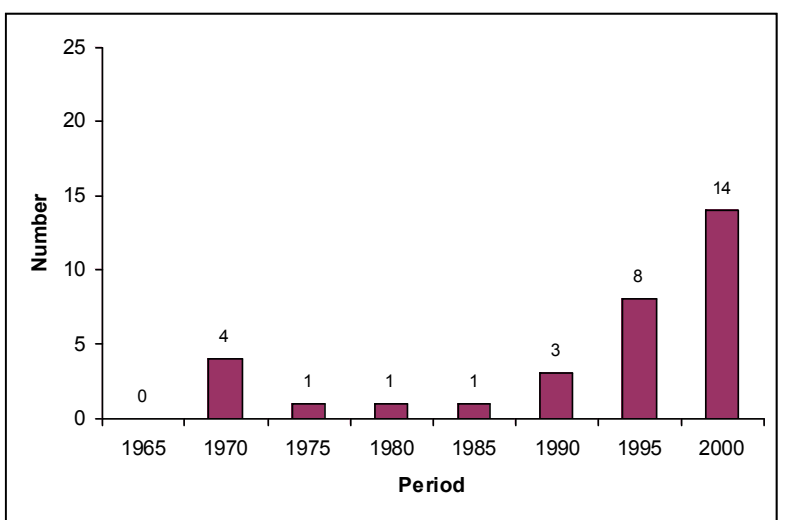

Figure A-4: Delivery

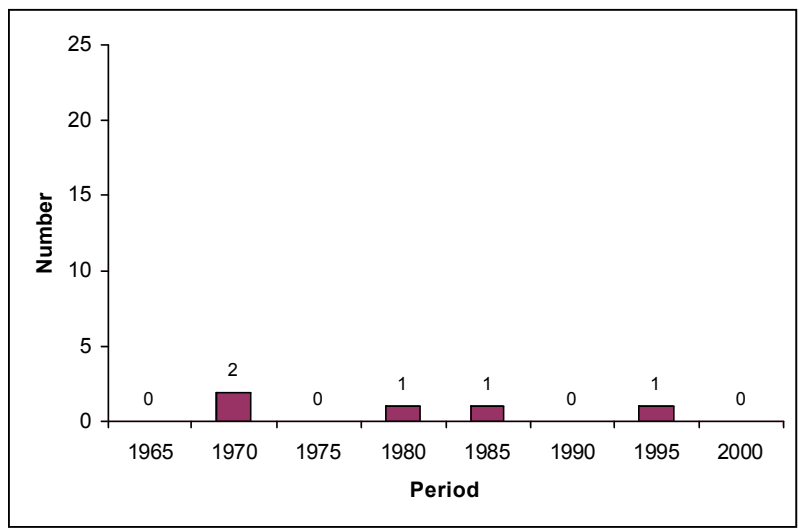

Figure A-5: Prevention

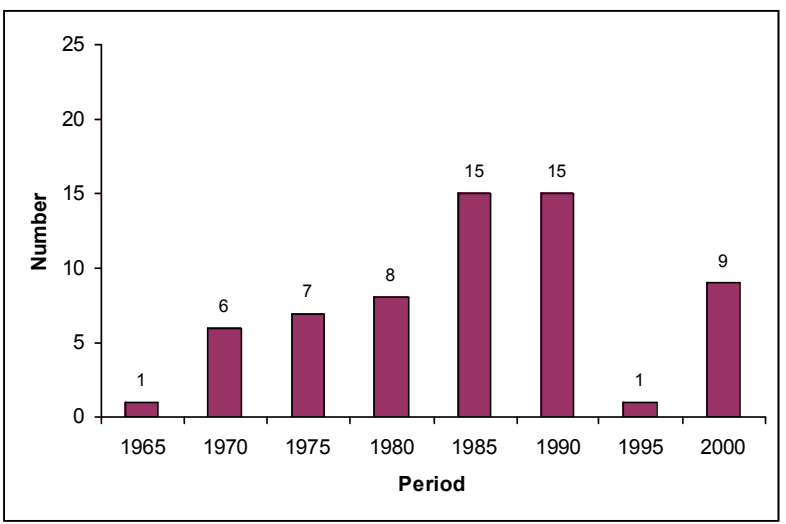

Figure A-6: Epidemiology

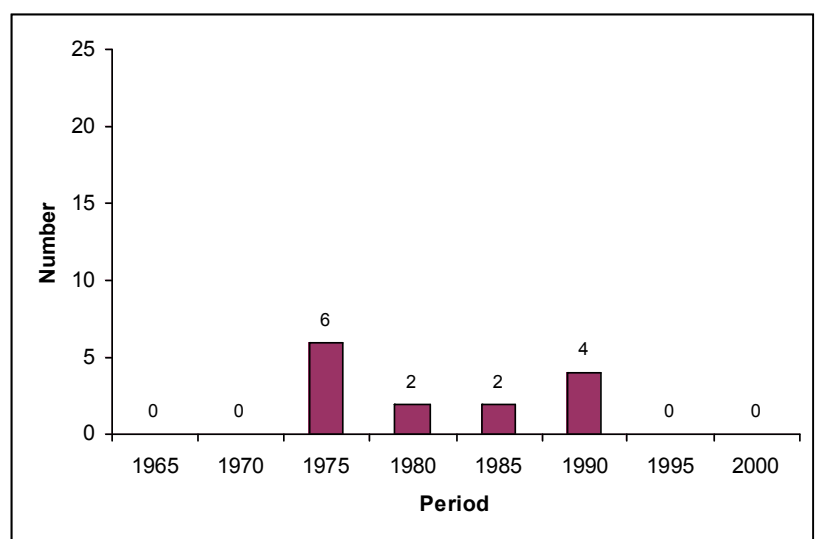

Figure A-7: Dental

\section{REFERENCES}

Hirsch, Gary, Jack Homer, Geoff McDonnell, and Bobby Milstein 2005. Achieving health Care reform in the United States: Toward a whole system understanding. (Draft version.) In Proceedings of 2005 International Conference of the System Dynamics Society.

Lane, D.C. 2000. You just don't Understand me: Modes of failure and success in the discourse between system dynamics and discrete event simulation. LSE OR Department Working Paper LSEOR 00-34, London School of Economics and Political Science.

Morecroft, John and Stewart Robinson 2005. Explaining puzzling dynamics: Comparing the use of system dynamics and discrete event simulation. In Proceedings of the 2005 International Conference of the System Dynamics Society.

Porter, Michael E. and Elizabeth Olmstead Teisberg 2004. Redefining competition in health Care, Harvard Business Review, Vol. 82, No. 6, pp. 64-76.

System Dynamics Society 2005. System Dynamics Bibliography.

Available

via

<http: / /www . albany . edu/cpr/sds/bibli

o/sdbib.html> [accessed May 24, 2005].

\section{AUTHOR BIOGRAPHIES}

C. PATRICK KOELLING is an associate professor in the Grado Department of Industrial and Systems Engineering at Virginia Tech. His research interests include system thinking, system modeling and analysis via simulation and optimization, particularly for problems in the U.S. health system. He is a Fellow of IIE and a member of INFORMS, ASQ, and ASEE. His e-mail address is <koellingavt.edu> and his Web address is <http://ise.vt.edu/koelling_page.htm>. 
MICHAEL J. SCHWANDT is a doctoral student in the Grado Department of Industrial and Systems Engineering at Virginia Tech. His research interests focus on system dynamics applications in industrial engineering. He is a registered professional engineer and a member of IIE and the System Dynamics Society. His e-mail address is $<$ schwandt@vt. edu>. 